\title{
8BOCEHM
}

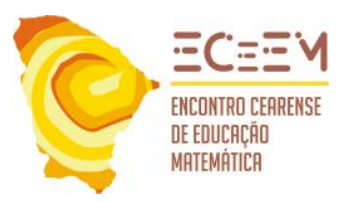

ISSN: 2447-8504 DOI: 10.30938/bocehm.v8i23.5133

\section{APLICANDO A SEQUÊNCIA FEDATHI NO ENSINO DA GEOMETRIA PLANA}

\author{
APPLYING THE FEDATHI SEQUENCE IN THE TEACHING OF FLAT GEOMETRY
}

\author{
Maria José Araújo Souza1
}

\begin{abstract}
RESUMO
Este trabalho trata do ensino da Geometria com base na proposta Sequência Fedathi. Teve como objetivo geral analisar influências da Sequência Fedathi no ensino da Geometria com o software Cabri-Géomètre. A metodologia da pesquisa foi desenvolvida com base na Sequência Fedathi. Os sujeitos pesquisados foram alunos da disciplina Novas Tecnologias no Ensino de Matemática do Curso de Licenciatura em Matemática da Universidade Estadual Vale do Acaraú - UVA, em Sobral - Ceará. A pesquisa constou da exploração das etapas da Sequência Fedathi e da aplicação de sequências didáticas utilizando Fedathi como proposta metodológica no ensino e aprendizagem da Geometria, através da resolução de atividades com o software Cabri-Geómètre. Ao final, podemos considerar que a Sequência Fedathi é um modelo de ensino que favorece a aprendizagem em matemática no ambiente informático, principalmente, pelas reflexões, compreensões e interações que propicia entre professor e alunos na elaboração deste saber.
\end{abstract}

Palavras-Chave: Geometria; Cabri-Géomètre; Sequência Fedathi.

\begin{abstract}
This work deals with the teaching of Geometry based on the proposed Fedathi Sequence. Its general objective was to analyze the influences of the Fedathi Sequence in the teaching of Geometry, with the Cabri-Géomètre software. The research methodology was developed based on the Fedathi Sequence. The researched subjects were students of the subject New Technologies in the Teaching of Mathematics of the Degree Course in Mathematics at the State University Vale do Acaraú - UVA, in Sobral - Ceará. The research consisted of the exploration of the steps of the Fedathi Sequence and the application of didactic sequences using Fedathi as a methodological proposal in the teaching and learning of Geometry, through the resolution of activities with the Cabri-Geómètre software. In the end, we can consider that the Fedathi Sequence is a teaching model that favors learning in mathematics in the computer environment, mainly due to the reflections, understandings and interactions that it provides between teacher and students in the elaboration of this knowledge.
\end{abstract}

Keywords: Geometry; Cabri-Géomètre; Sequência Fedathi.

\footnotetext{
${ }^{1}$ Doutora em Educação (UFC). Professora do Curso de Licenciatura em Matemática da Universidade Estadual Vale do Acaraú (UVA), Sobral, Ceará, Brasil. Endereço: Rua Paulo Franklin Barbosa, nº 190, Junco, Sobral-Ceará, CEP: 62.030-300. E-mail: mazesobral@yahoo.com.br.

(iD) ORCID iD: https://orcid.org/0000-0001-5083-7122.
} 


\section{Introdução}

A ideia de que a Matemática oferece mais obstáculos à aprendizagem do que as demais disciplinas é certamente muito antiga e por isso mesmo tem merecido, nos últimos anos, especial atenção por parte dos educadores matemáticos, asserção comprovada pelo aumento de eventos, publicações e grupos de pesquisa em torno do tema.

Apesar da atenção que vem sendo dada à questão, as dificuldades para que transformações venham ocorrer no ensino desta ciência estão ligadas a vários fatores, entre os quais podemos ressaltar a prática docente, a qual é uma forte barreira para que mudanças significativas sejam produzidas no âmbito das salas de aula.

Diversos fatores, mitos e crenças que muitos professores têm acerca da Matemática, o baixo domínio teórico-metodológico na área, utilização inadequada de instrumentos e materiais de apoio, falta de visão mais ampla e global acerca das transformações e mudanças sociais, entre outros fatores, são determinantes e estão intimamente relacionados ao baixo nível de aprendizagem da matéria. Neste sentido, o papel do professor passa a ser determinante, tendo como função precípua elaborar saberes, que preparem os alunos para lidar de maneira satisfatória com esta nova sociedade, marcada por diferentes formas e estilos de vida, rápidas transformações e muita tecnologia.

Sabemos que os conteúdos escolares são propostos no currículo sob a influência dos cenários político e social do meio onde estão inseridos. Nesta realidade, a Matemática que temos hoje na escola decorre da influência de movimentos sociais e educacionais, nacionais e internacionais, os quais determinam o que os alunos devem estudar.

Em relação à Geometria, mesmo com sua notável importância prática e intelectual, sua presença foi praticamente abolida dos currículos escolares nas décadas de 1960 a 1980, em decorrência do Movimento da Matemática Moderna, conhecido como MMM, que primou pelo ensino da Álgebra e outras áreas da Matemática, em detrimento da Geometria. Em 1997, os Parâmetros Curriculares Nacionais - PCN's e em 2018 a Base Nacional Curricular Comum $\mathrm{BNCC}$, resgataram a Geometria para as propostas curriculares e livros didáticos, retomando seu ensino na educação básica.

Com base no cenário descrito, o presente trabalho (oriundo de reflexões em nossa tese de doutorado) tem como objetivo apresentar e discutir aspectos ligados à aplicação da proposta 
de ensino Sequência Fedathi no ensino da Geometria Plana, mediado pelo software CabriGeometre $^{2}$.

\section{A Sequência Fedathi}

Borges Neto (2001) propõe uma sequência metodológica para o ensino e pesquisa em Matemática, denominada Sequência Fedathi. O modelo pressupõe a realização de quatro fases sequenciais e interdependentes, denominadas:

1) Tomada de posição - apresentação do problema. Nesta etapa é feita abordagem inicial através de contextualização da situação-problema apresentada.

2) Maturação - compreensão e identificação das variáveis envolvidas no problema.

3) Solução - representação e organização de esquemas/modelos que visem à solução do problema. Nesta ocorre a discussão das soluções elaboradas pelos alunos, buscando identificar os possíveis erros e qual solução mais indicada para o problema.

4) Prova - formalização do modelo matemático a ser ensinado.

Importante destacar que para Borges Neto (1999), nas etapas de aplicação da Sequência Fedathi, ao deparar um problema novo, o aluno deve reproduzir os passos que um matemático realiza quando se debruça sobre seus ensaios: aborda os dados da questão, experimenta vários caminhos que possam levar a solução, analisa possíveis erros, busca conhecimentos para constituir à solução, testa os resultados para saber se errou e onde errou, corrige-se e monta um modelo.

A Sequência Fedathi é uma proposta de ensino vem sendo estudada e experimentada por estudantes e pesquisadores de várias áreas, sendo a área de matemática a mais trabalhada, pelo fato de ser a área de formação de seu autor.

\section{Desenvolvimento da Pesquisa}

A pesquisa apresentada neste trabalho é um recorte do experimento realizado com 76 alunos da disciplina "Novas Tecnologias no Ensino da Matemática”, no semestre 2009-1 (no período foram divididos em duas turmas, cada uma com 38 alunos), à época, ofertada no sétimo período do Curso de Licenciatura em Matemática da UVA. O experimento foi realizado

\footnotetext{
${ }^{2} \mathrm{O}$ Cabri permite ao professor criar livremente atividades para suas aulas, ele é assim caracterizado como um software aberto. Ele pode ser utilizado desde o primário até a Universidade em diversas áreas como Matemática, Física e Desenho Artístico por exemplo. O Cabri-Géomètre é um software desenvolvido por J. M. Laborde, Franck Bellemain e Y. Baulac, no Laboratório de Estruturas Discretas e de Didática. https://software.com.br/p/cabri-geometreniversidade de Grenoble. Este é um laboratório associado ao CNRS, instituição francesa equivalente ao CNPq brasileiro. Disponível em 〈https://software.com.br/p/cabri-geometre $>$. Acesso: 02 de mar. 2021.
} 
através da aplicação de 4 (quatro) sessões didáticas explorando conceitos da geometria plana, com o software Cabri-Géomètre, com base na proposta metodológica Sequência Fedathi. Cada sessão sessão didática foi trabalhada de forma presencial, durante duas horas, no Laboratório de Informática do Curso de Matemática. Ressaltamos que o experimento foi realizado pela autora, que era também professora da disciplina no período da realização do experimento.

\section{Aplicação da Sequência Fedathi}

Neste trabalho, apresentaremos apenas a aplicação da Sequência Fedathi na Sequência Didática 1. O tópico tem como objetivo ressaltar aspectos das intervenções realizadas em cada uma das etapas da Sequência Fedathi. Este detalhamento é apresentado apenas sobre a atividade 1, por serem similares aos realizados nas outras 3 sessões didáticas. O objetivo deste tópico é enfatizar as interações e intervenções realizadas de acordo com os fundamentos da Sequência Fedathi.

\section{$1^{\circ}$ Etapa - Tomada de Posição}

Iniciamos uma sondagem sobre quem tinha experiência em informática e em quais softwares, todos eles disseram que tinham alguma experiência, alguns ressaltaram que tinham, mas ainda se consideravam aprendizes. Entre as principais atividades desenvolvidas pelo grupo no computador, foram citadas: pesquisa na Internet, correio eletrônico, redes sociais, editores de texto e poucos com planilha eletrônica. Após este diagnóstico, fizemos a apresentação do software Cabri-Géomètre, seus menus e suas principais funções. Logo depois demos aproximadamente 20 minutos para os alunos manipularem o programa e tirarem dúvidas.

Após as primeiras explorações com o software entregamos uma folha para cada um com a atividade a ser trabalhada. Orientamos a classe, no sentido de que nos primeiros 15 minutos, tentassem resolver a questão de maneira individual, e só depois, fossem trocar idéias com os colegas, caso preferissem, poderiam continuar resolvendo de forma individual. A atividade apresentada ao grupo foi:

\begin{tabular}{|c|}
\hline ATIVIDADE 1 \\
\hline Construa um quadrado ABCD \\
\hline
\end{tabular}

\section{$2^{\circ}$ Etapa - Maturação}

Iniciamos a etapa da maturação, passando pelos grupos, acompanhando seus primeiros registros na busca da solução. Observamos que inicialmente, todas as resoluções se baseavam 
na construção do quadrado mediante a união de segmentos, que eram arrastados até atingir medidas iguais. Vale ressaltar que todos eram desenhados sempre com a figura na posição reta, o que denota um conhecimento ligado à aparência e a forma, e, menos, à propriedade do objeto, conforme figura 1 abaixo.

Figura 1: Estilo de resolução da Atividade 1

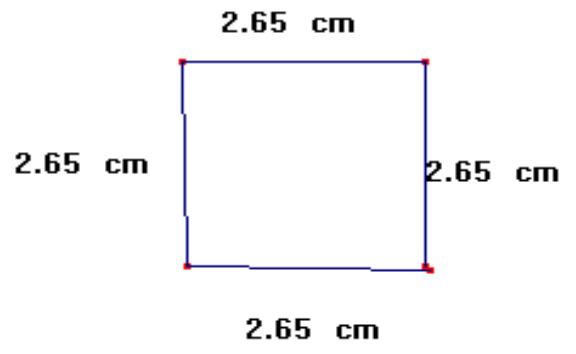

Fonte: Autoria própria

Nenhuma solução mostrava o quadrado inclinado. Então apresentamos ao grupo um quadrado, na posição reta conforme Figura 2. Logo depois, como contraexemplo, inclinamos o quadrado, conforme Figura 3 e indagamos se ainda continuava sendo quadrado, pelo menos $50 \%$ dos 76 alunos pesquisados, afirmaram que não, e que a figura era agora um losango.

Figura 2: Ouadrado na

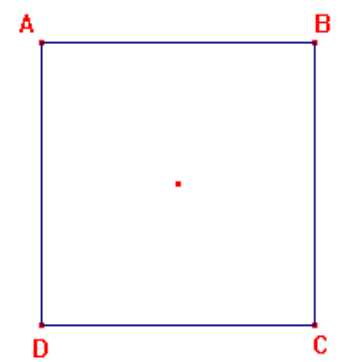

Figura 3: Quadrado posição reta na posição inclinada

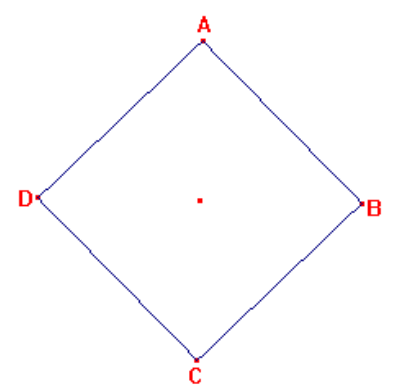

Fonte: Autoria própria

Perguntamos como podiam nos justificar tal afirmação. Alguns dos que afirmaram que era losango ficaram calados e pensativos. Os que tentaram justificar começaram argumentando que a posição dos vértices determinava o losango. Perguntamos o que havia mudado do quadrado para o losango, se alguma propriedade havia sido alterada com a mudança de posição. Só então começaram a dizer que não, e perceberam que realmente a figura continuava sendo a mesma. Solicitamos que movimentassem a figura e observassem que tipo de alterações e transformações ocorriam com as figuras construídas. 
Após esta discussão, continuamos passando junto aos grupos, observando suas construções, tirando dúvidas e fazendo indagações sobre elas. Neste acompanhamento, a maioria dos alunos nos perguntavam se a sua solução estava correta. Sempre que nos perguntavam, fazíamos a seguinte pergunta: "quais as propriedades que compõem o quadrado”? A resposta apresentada era a de que o quadrado possui quatro lados iguais e quatro ângulos retos. Perguntamos então, se eles haviam verificado a medida dos ângulos de seus quadrados. A maioria respondeu que não (já havíamos observado que nenhum havia medido os ângulos de suas figuras, talvez por desconhecerem como realizar tal ação junto ao software Cabri-Géomètre). Explicamos como realizar a medição de ângulo junto ao software; relembramos também o conceito de ângulo. Notamos que a representação que os alunos possuem sobre ângulo está ligada ao vértice - geralmente o ângulo é identificado somente pelo ponto de seu vértice, no caso do ângulo $\mathrm{DÂB}$, destacado na figura 4; geralmente, o ângulo é visualizado pelos alunos como sendo apenas o ponto A e não a região determinada pela união dos segmentos $\overline{\mathrm{BA}}$ e $\overline{\mathrm{DA}}$.

\section{Figura 4: Ângula DÂB}

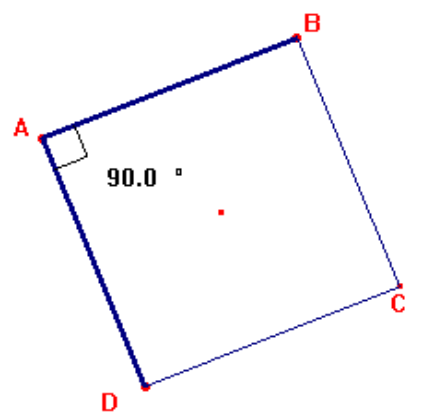

Fonte: Autoria própria

Ainda na etapa da Maturação, enquanto trabalhavam nas soluções, observamos que, após algumas explicações e dúvidas esclarecidas, as construções eram estruturadas e apresentavam-se de formas diferentes, variando de acordo com o nível de conhecimento matemático de cada aluno.

\section{$3^{0}$ Etapa - Solução}

Iniciamos a discussão das resoluções nos pequenos grupos ainda na fase da maturação e socializamos os vários tipos de resposta na etapa da solução. As soluções apresentadas foram socializadas com todo o grupo e nomeadas como Solução $\boldsymbol{A}, \boldsymbol{B}, \boldsymbol{C} \boldsymbol{e} \boldsymbol{D}$, as quais apresentamos 
logo abaixo, juntamente com as reflexões e sugestões suscitadas desde suas concepções iniciais nos pequenos grupos (na maturação) até a discussão destas junto ao grupão.

Quadro 1: Solução A

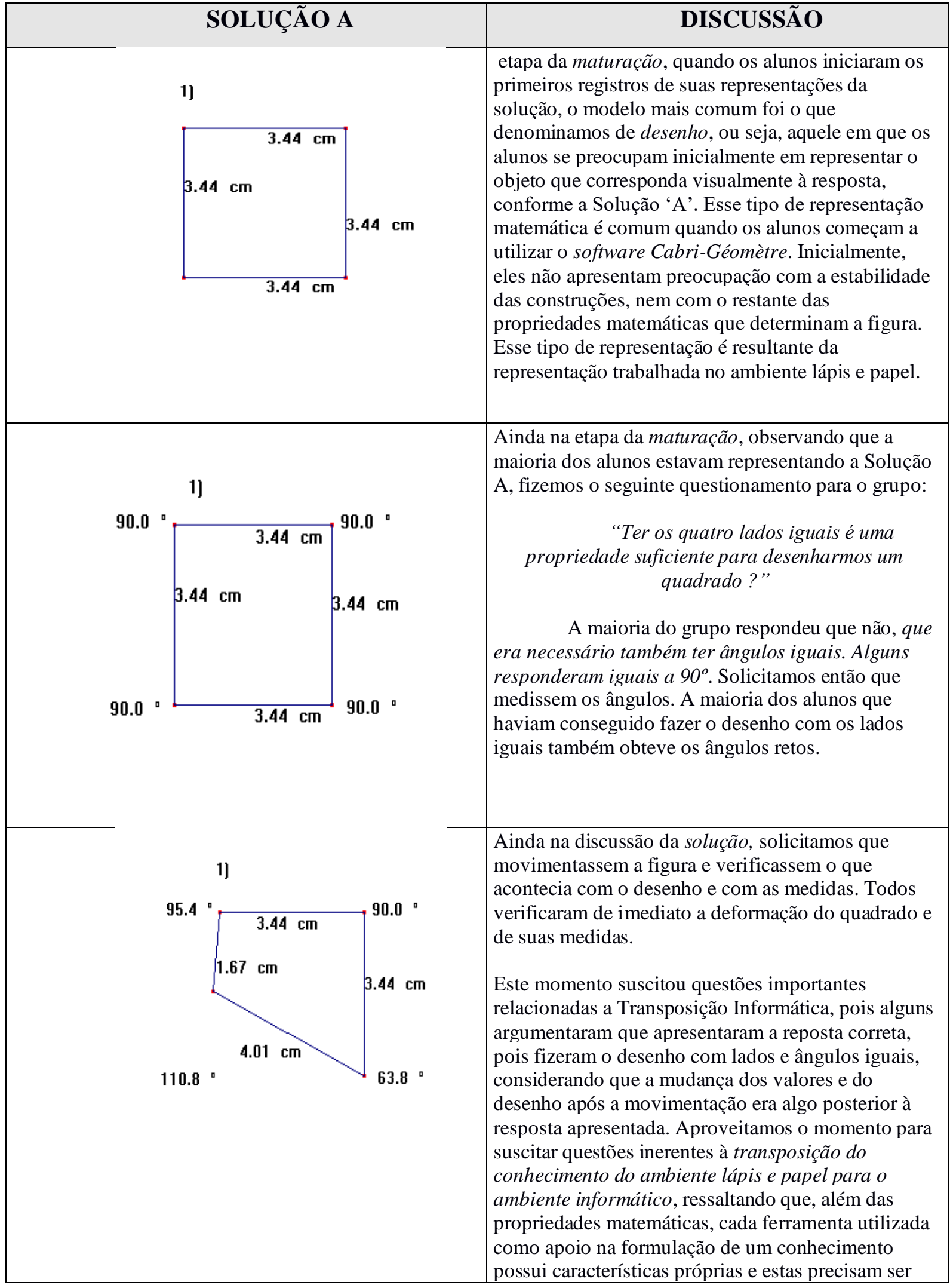




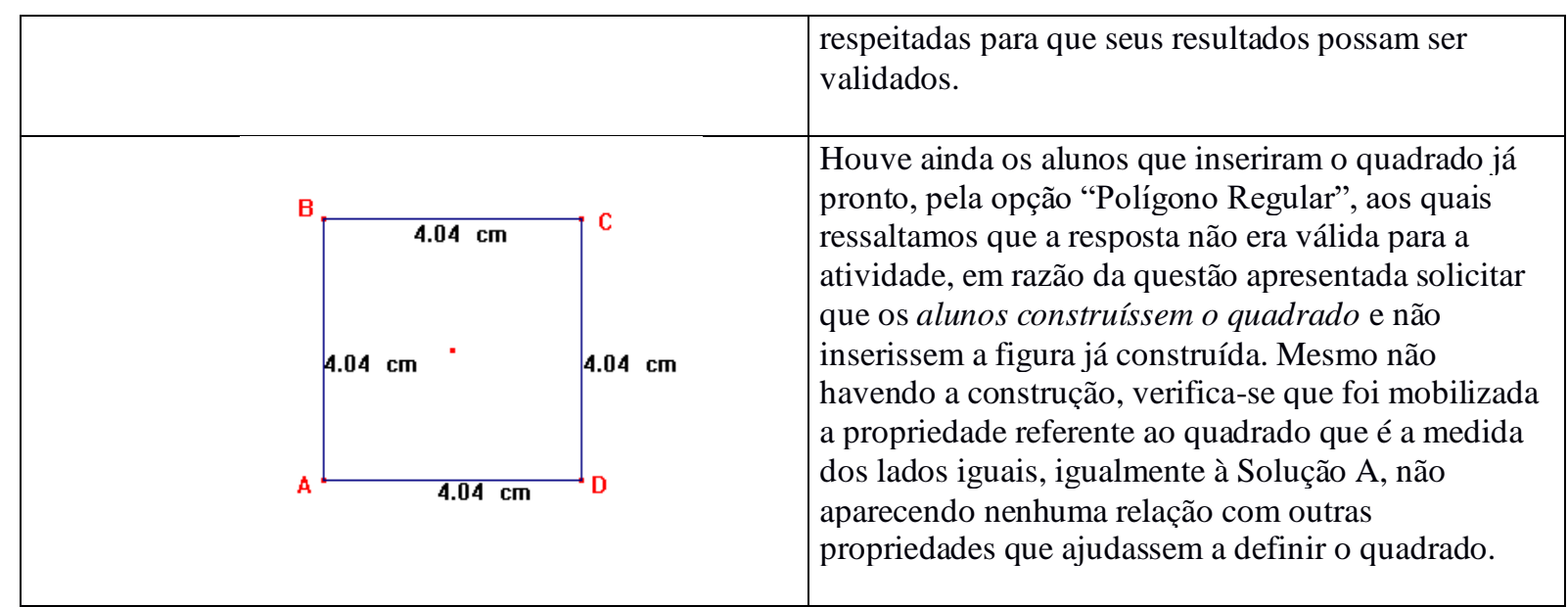

Fonte: Dados obtidos nas soluções da Sequências Didática 01

O modelo da resolução apresentado na Solução A é bastante comum como resposta ao tipo de atividade apresentada, seja no ambiente lápis e papel ou em ambientes informáticos da Geometria Dinâmica. A forma e as propriedades apresentadas nos mostram como a aprendizagem da Geometria ainda é superficial, ou seja, o ensino acaba deixando uma visão acerca da relação dos objetos geométricos com sua aparência e não com suas propriedades. Apesar dos sujeitos pesquisados possuírem formação específica na área de Matemática e parte deles já serem professores, na solução que prevaleceu (Solução A), predominou apenas a propriedade referente aos lados, ou seja, terem que ser iguais, sem menção às propriedades.

A aplicação da Sequência Fedathi foi determinante para a evolução do conhecimento dos alunos nas fases da maturação e solução, momentos em que o professor aproveitou as dúvidas, perguntas e representações manifestadas pelos alunos, levando-os a refletir sobre suas hipóteses e a realizar comparações e experimentações sobre estas produções.

Quadro 2: Solução B

\begin{tabular}{|c|c|}
\hline SOLUÇÃO B & DISCUSSÃO \\
\hline 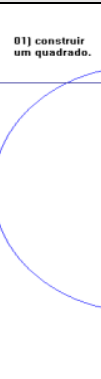 & $\begin{array}{l}\text { A Solução B foi outro tipo levantado por alguns } \\
\text { alunos. Esta já é uma solução mais elaborada, onde } \\
\text { podemos perceber que os alunos estão aplicando } \\
\text { conceitos ligados às construções geométricas, } \\
\text { considerando a medida do raio da circunferência para } \\
\text { garantir a igualdade nas medidas dos lados do } \\
\text { quadrado; no entanto, não houve atenção inicial do } \\
\text { aluno para visualizar que os lados } \overline{\mathrm{BC}} \text { e } \overline{\mathrm{AD}} \text { eram } \\
\text { menores do que a medida do raio das circunferências. }\end{array}$ \\
\hline
\end{tabular}




\begin{tabular}{|l|l|}
\hline $\begin{array}{l}\text { Ainda na fase da maturação, quando o aluno nos } \\
\text { perguntou se a construção estava correta, solicitamos } \\
\text { que ele fizesse a medição dos lados e dos ângulos, } \\
\text { movimentasse a construção e observasse se haveria } \\
\text { alguma transformação na figura, e quais. } \\
\text { Após realizar as alterações, ele nos chamou } \\
\text { novamente, dizendo que a medida dos ângulos } \\
\text { estavam iguais e continuaram mesmo com a } \\
\text { movimentação, no entanto a medida dos lados estava } \\
\text { diferente. Observamos que ele ainda não havia } \\
\text { percebido que os lados BC e AD não correspondiam } \\
\text { ao raio das circunferências. }\end{array}$ \\
\hline $\begin{array}{l}\text { Este outro aluno optou pelo mesmo tipo de construção } \\
\text { do aluno anterior, no entanto, sua construção estava } \\
\text { correta. Na etapa da solução, quando discutimos as } \\
\text { representações das soluções encontradas, este aluno } \\
\text { nos perguntou se havia outra forma de verificar se a } \\
\text { construção estava correta, que não fossem as medições } \\
\text { dos lados e ângulos e a movimentação da figura. } \\
\text { Respondemos que o Cabri possui no menu Verificar } \\
\text { Propriedades e o ajudaria a encontrar a resposta. }\end{array}$ \\
\hline and
\end{tabular}

Fonte: Dados obtidos nas soluções da Sequências Didática 01

O modelo de representação da Solução B foi apresentado apenas por quatro dos 76 alunos. Podemos observar que se trata de uma solução mais elaborada e requer do aluno maior conhecimento acerca de conceitos e propriedades geométricas. Foram mobilizados nesta solução conceitos ligados a circunferência, perpendicularismo, paralelismo, ângulos $e$ construções geométricas.

Quadro 3: Solução C

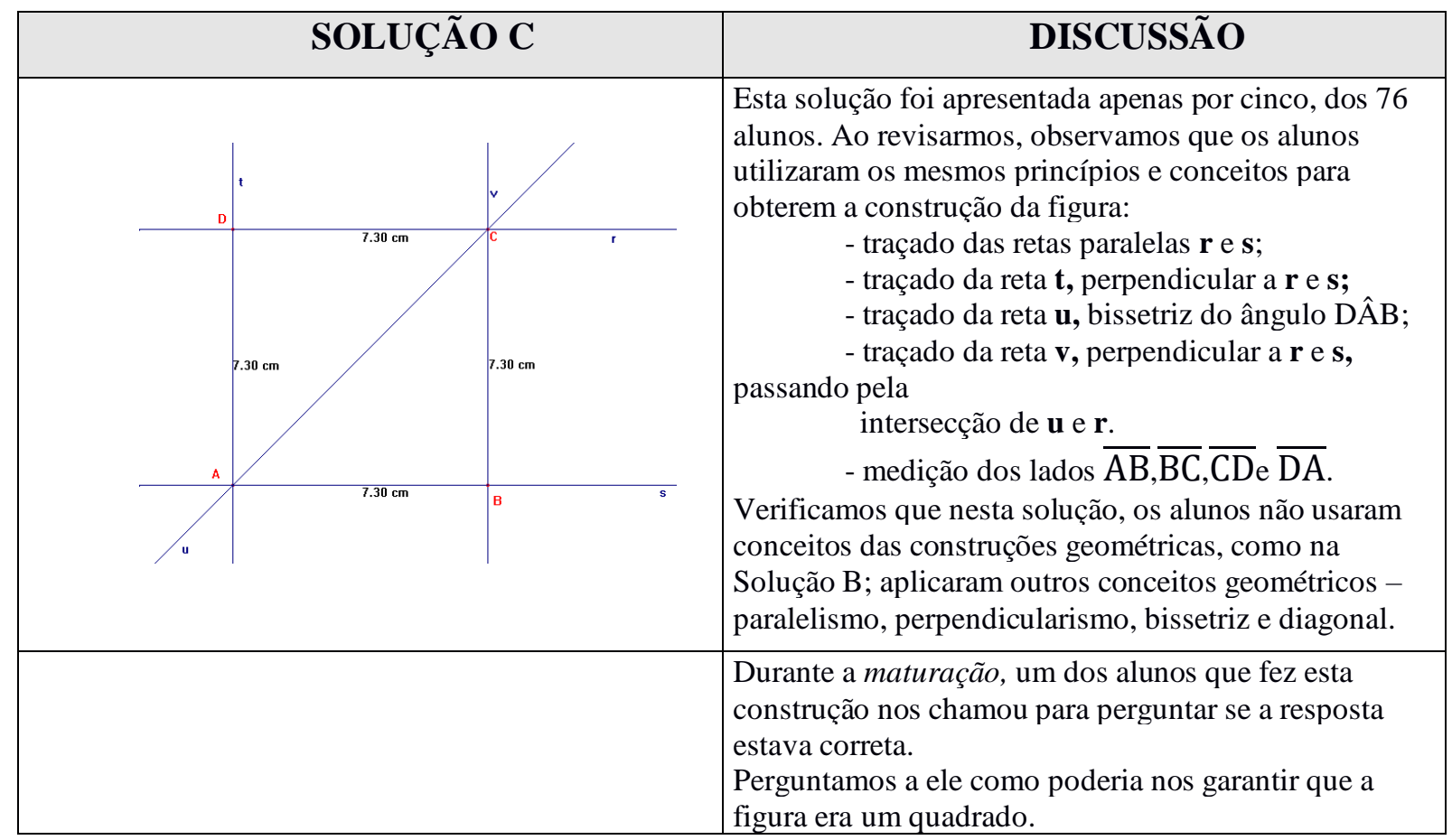




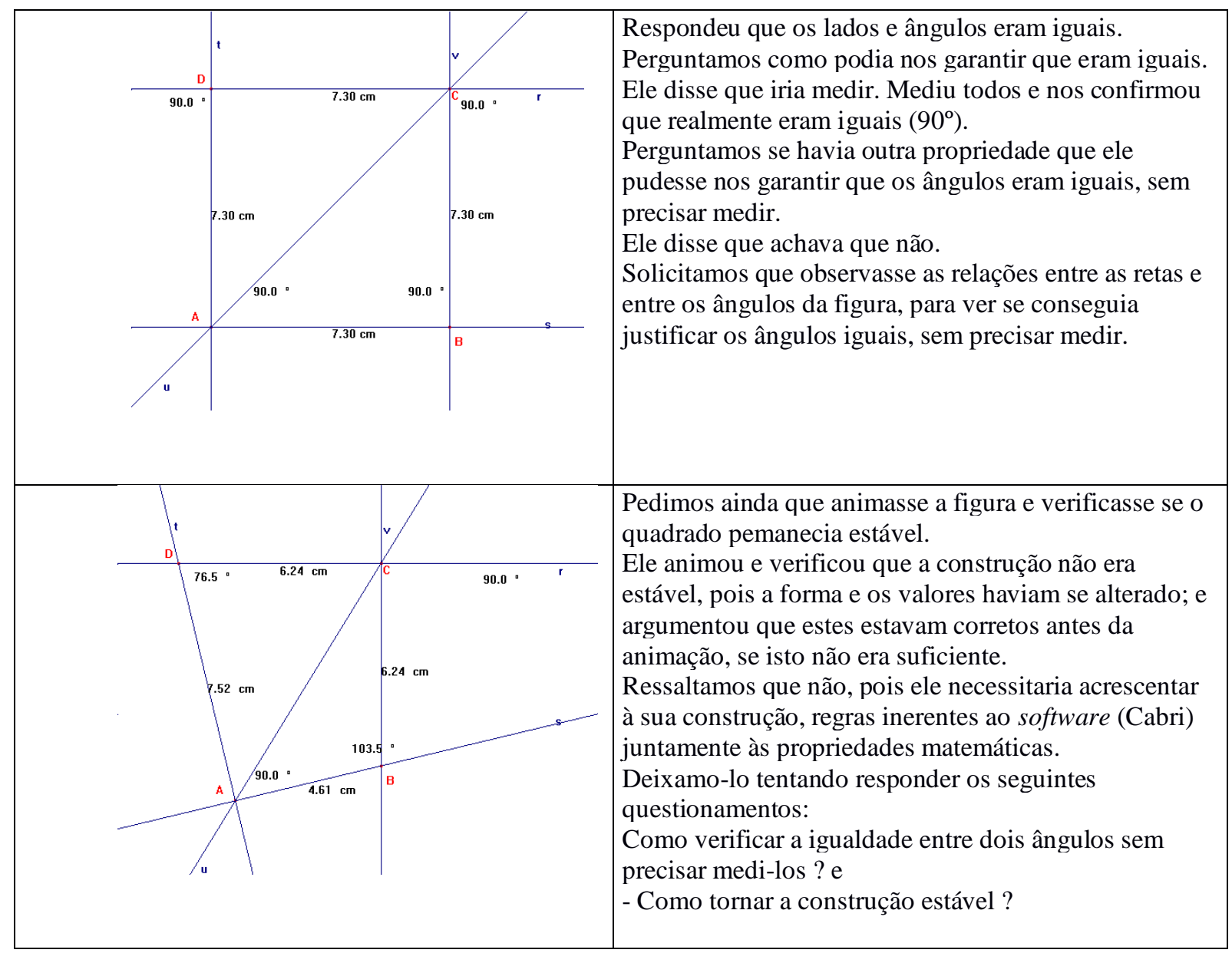

Fonte: Dados obtidos nas soluções da Sequências Didática 01

Podemos perceber que a Solução C não está diretamente ligada a modelos de construções geométricas, aproximando-se das resoluções tipicamente exploradas no ambiente lápis e papel, mostrando-se como uma tentativa de transposição direta da mesma abordagem para o ambiente informático. Apesar de não envolver diretamente os típicos modelos de construção geométrica, a solução requer o domínio de vários conceitos da Geometria plana, sendo eficiente, principalmente nos primeiros contatos com o Cabri, quando os alunos ainda estão se familiarizando com suas ferramentas, suas possibilidades e potencialidades na elaboração das soluções.

Percebemos que a utilização de construções geométricas como base para as soluções, torna-se certo obstáculo para alguns alunos nos contatos iniciais com os softwares de Geometria Dinâmica, principalmente para os que não possuem domínio de seus conceitos, ou muito pouco conhecimento acerca destas construções. É importante que o professor esteja atento em relação a este aspecto, para não prejudicar o saber que pretende consolidar com seus alunos, necessitando, talvez, acrescentar a seu planejamento, a exploração de conceitos acerca das construções geométricas, de maneira paralela aos conceitos geométricos estudados. 
Durante a discussão das construções apresentadas pelos grupos, procuramos incentivar os alunos a justificar suas soluções, buscando mostrar-lhes os pontos em que haviam cometido erros, tanto com relação aos conceitos matemáticos, como à implementação da solução no ambiente do Cabri. Chamamos a atenção para a representação correta dos objetos geométricos, pois muitas das soluções não apresentavam nomeação dos objetos.

\section{$4^{\circ}$ ETAPA - PROVA}

Ainda na etapa da solução, quando discutimos as soluções apresentadas pelos grupos, alguns alunos nos perguntaram qual seria a forma correta de construir o quadrado. Respondemos que não havia uma só forma e que em sua maioria as soluções apresentadas estavam corretas do ponto de vista conceitual, muitos dos erros que apresentavam, não eram da solução escolhida e sim, da implementação da solução no ambiente informático, neste caso, no Cabri.

Explicamos ao grupo que muitos dos erros que havíamos detectado estavam ligados a relação dos objetos, ou seja, das intersecções de pontos, retas e circunferências, da visualização dos objetos, onde as relações de intersecção ou sobreposição só eram percebidas, na maioria das vezes, quando as figuras eram movimentadas.

Mostramos ao grupo uma das soluções que podiam ser consideradas como correta, pois, além de incorporar as propriedades do quadrado, mostrava facilmente sua validade em razão das relações e valores proporcionados pela circunferência (raio) e sua relação com as retas paralelas e perpendiculares (Solução D).

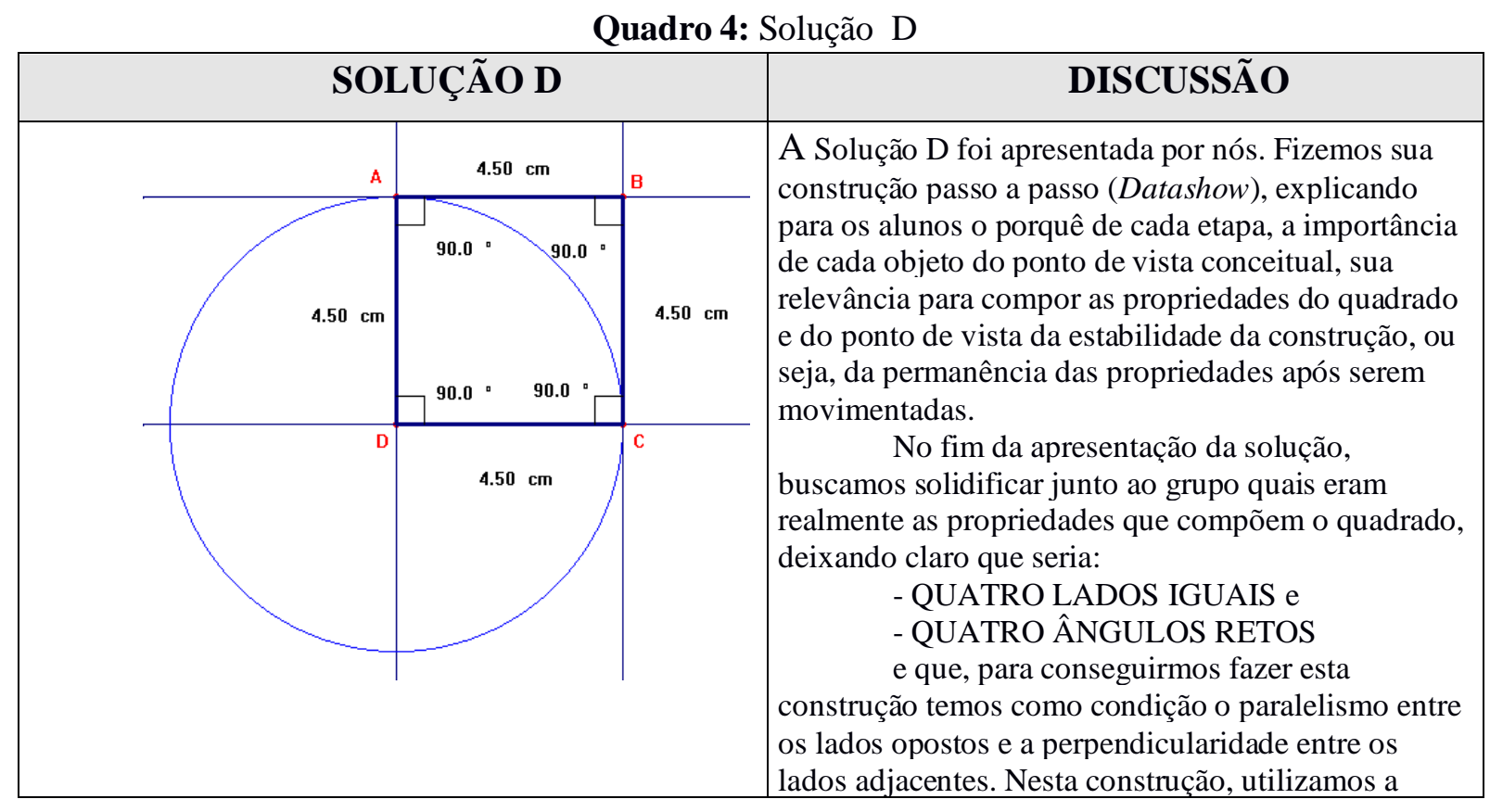


circunferência para garantir as medidas iguais entre os lados, por meio da medida do raio.

Após apresentar a nossa solução, fizemos algumas animações da figura, a fim de verificar a estabilidade da construção, ou seja, a permanência das propriedades e não deformação do quadrado. $\mathrm{Na}$ construção, ressaltamos a importância da observação das etiquetas que aparecem com mensagens na tela do Cabri, referentes aos objetos. Explicamos que a atenção a estas mensagens no ato da construção, é determinante para a construção correta e a estabilidade das figuras.

Fonte: Dados obtidos nas soluções da Sequências Didática 01

Após a discussão das soluções por nós apresentadas, solicitamos aos alunos que refizessem sozinhos a mesma construção, a fim de apreenderem o modelo geral e, se necessário, tirarem suas dúvidas. Orientamos no sentido que, sempre que concluíssem uma construção, buscassem animá-la ou movimentá-la como forma de verificar se esta permanecia estável, ou seja, se estava correta para os ambientes da Geometria Dinâmica. Buscamos através dos protocolos apresentados, ilustrar algumas ações vivenciadas durante a aplicação da sequência didática 01, enfatizando as mediações e interações realizadas com base nos princípios da Sequência Fedathi.

\section{Conclusões}

A Sequência Fedathi foi para nós, uma metodologia que muito se adequou e muito contribuiu para o ensino da geometria com o Cabri-Géométre, seu modelo possibilitou um trabalho significativo tanto para nós, como para os alunos, que além de haverem alcançado os objetivos propostos nas sequências didáticas, relataram que o trabalho realizado ficou sendo um modelo para aplicarem nas escolas que lecionam/lecionarão. Percebemos que a vivência de cada uma das fases propiciou um excelente desenvolvimento das atividades, isto porque o ensino da matemática utilizando tecnologia requer do professor uma nova postura perante a elaboração do saber. É preciso que o professor perceba que os conceitos matemáticos, quando explorados no computador, adquirem novas formas de apresentação e formulação. A experimentação passa a ser um elemento enriquecedor para o aluno, que passa realmente a desenvolver um trabalho similar ao do matemático. Neste sentido, é preciso que o professor organize a gestão do tempo das aulas, para conseguir concretizar os objetivos de ensino perseguidos. 


\section{Referências}

BORGES NETO, H. \& DIAS, A.M I. Desenvolvimento do raciocínio lógico-matemático no $1^{\circ}$ Grau e Pré-Escola. Cadernos da Pós-Graduação em Educação: Inteligência-enfoques construtivistas para o ensino da leitura e da matemática. Fortaleza, UFC, 1999.

BORGES NETO, H. et all. A Sequência de Fedathi como proposta metodológica no ensino-aprendizagem de matemática e sua aplicação no ensino de retas paralelas. In: Encontro de Pesquisa Educacional do Nordeste. Educação - EPENN, 15, São Luís, Anais, 2001.

SOUZA, M.J.A. Aplicações da Sequência Fedathi no ensino e aprendizagem da geometria mediado por tecnologias digitais. 2010. 230f. Tese (Doutorado) - Universidade Federal do Ceará, Faculdade de Educação, Programa de Pós-Graduação em Educação Brasileira, Fortaleza, 2010. 